\title{
Distribution of Adenosine Deaminase Activity in Rat Brain and Spinal Cord
}

\author{
Jonathan D. Geiger* and James I. Nagy $\dagger$ \\ Departments of *Pharmacology and †Physiology, University of Manitoba Faculty of Medicine, Winnipeg, \\ Manitoba R3E OW3, Canada
}

The activity of adenosine deaminase (ADA) was measured in 62 discrete regions of the CNS, and in some autonomic and sensory ganglia, peripheral nerves, and peripheral tissues of the rat using an automated high-pressure liquid chromatography (HPLC) method. The formation of inosine and hypoxanthine as a measure of ADA activity in homogenates of brain was optimal at pH 7.0 , linear for up to $60 \mathrm{~min}$ at $37^{\circ} \mathrm{C}$ using $500 \mu \mathrm{M}$ adenosine as substrate, and linear with protein concentrations ranging from 0.05 to $0.8 \mathrm{mg}$. The $K_{\mathrm{m}}$ and $V_{\max }$ values for $\Lambda \mathrm{D \Lambda}$ activity in homogenates of whole brain were $47 \mu \mathrm{M}$ and 107 $\mathrm{nmol} / \mathrm{mg}$ protein $\mathbf{3 0} \mathrm{min}$, respectively. Among the CNS regions examined, the highest activity was found in posterior hypothalamic magnocellular nuclei and the lowest in hippocampus. In general, spinal cord contained relatively low levels of $\mathrm{ADA}$ activity, with that in dorsal cord approximately $40 \%$ higher than ventral cord. In the periphery, parasympathetic ganglia contained higher levels of ADA than sensory ganglia and brain. Most peripheral tissues - including adrenal gland, lung, liver, and anterior and posterior pituitary-exhibited activity comparable to levels in the posterior hypothalamus. ADA activity in thymus was about 10 times higher than any other tissue examined.

The uneven distribution of ADA activity in the rat CNS corresponds well with the immunohistochemical localization of this enzyme in discrete neural systems of this species. Structures that contain high ADA activity exhibit intense ADA immunostaining of neuronal perikarya and/or fibers. The 13 -fold difference between brain regions containing the highest and lowest ADA activity suggests that, in addition to its involvement in intermediary metabolism, this enzyme may have an important role in regulating the putative neuromodulatory actions of adenosine in the CNS.

Adenosine deaminase (ADA; Adenosine aminohydrolase, EC 3.5.4.4) is responsible for the deamination of adenosine to the physiologically less active compound inosine. Various forms of this cytosolic enzyme have been identified with molecular weights of 36,000,1 14,000, and 298,000 (Van der Weyden and Kelley, 1976). By complexing with a membrane-bound binding protein, low-molecular-weight ADA is convertible to the large form of the enzyme. The binding protein does not itself express enzy-

\footnotetext{
Received Nov. 18, 1985; revised Feb. 18, 1986; accepted Mar. 10, 1986.

We thank Mr. Mark Whittaker and Ms. Kosala Sivananthan for their excellent technical assistance, and Ms. Barb Hunt and Ms. Cheryl Baraniuk for typing the manuscript. This work was supported by grants from the Medical Research Council of Canada (MRCC), Manitoba Health Research Council (MHRC), and the Health Sciences Centre Research Foundation. JIN and JDG are Scholars of the MRCC.

Correspondence should be addressed to Dr. Jonathan D. Geiger, Department of Pharmacology, University of Manitoba, Faculty of Medicine, 770 Bannatyne Avenue, Winnipeg, Manitoba R3E 0W3, Canada.

Copyright (c) 1986 Society for Neuroscience $0270-6474 / 86 / 092707-08 \$ 02.00 / 0$
}

matic activity, and its physiological function remains unclear (Andy and Kornfeld, 1982). Several lines of investigations on the cellular metabolism of purines in peripheral tissues have generated considerable interest in ADA. The recognition that elevated levels of adenosine and deoxyadenosine are cytotoxic to certain cell types suggests an important contribution by ADA to the maintenance of appropriate cellular adenine nucleoside and nucleotide concentrations (Fox and Kelley, 1978). The discovery that some patients with severe combincd immunodeficiency disease (SCID) are genetically deficient in ADA activity points to a crucial role of this enzyme in cells of the immune system (Daddona et al., 1983; Giblett et al., 1972). The use of adenine nucleoside analogs as chemotherapeutic agents has led to the development of potent ADA inhibitors, which, given in conjunction with these agents, prevent their deamination and prolong their effectiveness (Agarwal et al., 1975). The availability of such inhibitors together with the consequences of ADA deficiency in patients suffering from SCID prompted clinical trials of these inhibitors as treatments for certain forms of leukemia (Major et al., 1981).

Our interest in the function of ADA in neural tissue was kindled by the recent flood of reports supporting the notion that adenosine serves in a neuromodulatory capacity in both the PNS and CNS (Phillis and Wu, 1981; Stone, 1981). Indirect evidence suggests that ADA may have a role analagous to other catabolic enzymes that participate in the regulation of both synaptoplasmic levels and the extracellular actions of transmitter substances. Thus, the depressive electrophysiological actions of adenosine when applied to central neurons are potentiated by the concomitant application of potent ADA inhibitors such as $2^{\prime}$-deoxycoformycin (DCF) or erythro-9-(2-hydroxy-3-nonyl) adenine and mimicked by the application of these inhibitors alone (Phillis and Wu, 1981; Phillis et al., 1979). Moreover, ADA inhibitors administered to animals produce behavioral effects similar to those of adenosine agonists and cause physiological responses that are thought to be mediated through the action of adenosine on its receptors (Phillis et al., 1984, 1985; Radulovacki et al., 1983). Anatomical evidence for a relationship between ADA and the neuromodulatory actions of adenosine is derived from recent immunohistochemical demonstrations of the uneven distribution of ADA-immunoreactive neurons in discrete neural systems in the rat CNS (Nagy and Daddona, 1985; Nagy et al., 1984a, b, 1985). Among these were ADA-containing preganglionic parasympathetic neurons (Senba et al., 1985a) which in the cat have been shown to have an adenosine neurotransmitter component (Akasu et al., 1984). Moreover, structures immunoreactive for ADA in rat brain were found to correspond closely to those exhibiting the greatest density of binding sites for ${ }^{3} \mathrm{H}$-nitrobenzylthioinosine $\left({ }^{3} \mathrm{H}-\mathrm{NBI}\right)(\mathrm{Nagy}$ et al., 1984a, b), a putative ligand for adenosine uptake sites.

The above findings, together with the now established concept that adenosinc acts as a ncuromodulator and/or neurotrans- 
mitter in CNS and some peripheral systems, warrant investigations aimed at elucidating the biochemical pathways governing the metabolism of adenosine in neural tissue. As a first step towards this goal we analyzed the characteristics and regional distribution of ADA in the rat CNS.

\section{Materials and Methods}

\section{Tissue dissections}

Male Sprague-Dawley rats weighing approximately $300 \mathrm{~g}$ were sacrificed by decapitation. The brain, spinal cord, and peripheral tissues were removed, placed on an ice-cold metal tray, and dissected freehand or from thick frozen sections as previously described (Geigcr and Nagy, 1984,1985 ), unless otherwise indicated.

Cortical areas were subdivided according to the atlas of Paxinos and Watson (1982), and all other areas were dissected according to the atlas of Koning and Klippel (1963). No attempt was made to dissect specific subnuclei of the thalamus other than medial and lateral geniculate nuclei. The rest of the thalamus was divided into anterior and posterior regions at a rostrocaudal level demarcated by the anterior border of the habenula, and each of these regions was subdivided into medial and lateral areas. The anterior thalamic regions contained nucleus medialis, parstenialis, anterior medialis, rhomboideus, and reuniens medially, and the remaining nuclei laterally. The posterior thalamic regions contained the caudal extensions of these nuclei as well as nucleus posteriormedianus, ventralis medialis, and parafascicularis medially; and nucleus posterior, posterior lateralis, and pretectalis laterally.

The hypothalamus was excised from whole brain and taken for assay as such or divided into anterior and posterior regions containing all of the preoptic-anterior hypothalamic areas and posterior hypothalamic nuclei, respectively. In addition, frozen sections of whole brain were used to further subdivide these regions into medial and lateral preoptic and anterior hypothalamic areas. The posterior hypothalamic magnocellular nuclei consisting of the tuberal, caudal, and postmammillary caudal magnocellular cell groups were dissected from more posterior sections. Samples of habenula contained both its medial and lateral subnuclei. Samples of reticular formation were obtained at the midbrain level. The hippocampal formation was dissected according to its CA1, CA2, CA3, and dentate gyrus subfields or with respect to its septotemporal axis. In the latter dissection, the hippocampus was cut into 6 scgments at right angles to its long axis. Tissue samples from the septal pole progressively to the temporal pole were designated segments $1-6$, respectively. All tissues for the regional analyses were immediately frozen on dry ice following dissection and stored at $-80^{\circ} \mathrm{C}$ until taken for assay. The dissection time was always less than $15 \mathrm{~min}$.

\section{Adenosine deaminase assay}

The assay method of Hartwick et al. (1978) was adapted for measurement of ADA activity. For characterization of the assay, experiments were conducted using either fresh whole brains or previously frozen CNS or peripheral tissues. Samples were homogenized with a Polytron (setting 6, $10 \mathrm{sec}$ ) in ice-cold Tris buffer $(\mathrm{pH} \mathrm{7.0,50} \mathrm{mm)} \mathrm{containing} 10$ $\mathrm{mM} \mathrm{MgCl}$. It was found that for dorsal and ventral roots and ganglia, preincubation for $30 \mathrm{~min}$ at $37^{\circ} \mathrm{C}$ with 10 units of collagenase (Type VII, Sigma Chem. Co., St. Louis, MO) was necessary to ensure disruption of connective tissue and uniform homogenization. The collagenase did not itself affect ADA activity or protein measurements. Homogenate sufficient for measurable ADA activity but that did not produce greater than $20 \%$ substrate depletion was added to reaction vessels $(250 \mu \mathrm{l}$ microcentrifuge tubes) containing $500 \mu \mathrm{m}$ adenosine in a total volume of $100 \mu \mathrm{l}$ Tris- $\mathrm{MgCl}_{2}$ buffer. Following incubation for $30 \mathrm{~min}$ at $37^{\circ} \mathrm{C}$, the reaction was stopped with $10 \mu \mathrm{l}$ of $20 \%$ trichloroacetic acid (TCA) and the incubation tubes centrifuged at $14,000 \times g$ for $2 \mathrm{~min}$. The reaction supernatant was transferred to microcentrifuge tubes, neutralized with a tri-n-octylamine : freon mixture $(55: 145$, vol $/ \mathrm{vol})$, agitated briefly using a vortex mixer, and recentrifuged. Filtration of the final aqueous phase through $0.2 \mu \mathrm{m}$ filters to remove debris that might interfere with the HPLC analysis was found to be unnecessary since over 5000 sample injections were accomplished before deterioration of the HPLC column occurred.

The aqueous layer (top) containing the compounds to be measured was chromatographed using a Waters HPLC system consisting of a WISP 710B autosampler, Automated Gradient Controller, 510 pump, 441 UV detector with a $254 \mathrm{~nm}$ filter, and a Shimadzu C-R3A plotter/ printer/integrator. The mobile phase consisting of $88 \% \mathrm{KH}_{2} \mathrm{PO}_{4}(0.01$
$\mathrm{M}, \mathrm{pH} 5.0$ ) and $12 \%$ methanol was filtered through a $0.45 \mu \mathrm{m}$ filter, degassed under reduced pressure, and pumped at $1.5 \mathrm{ml} / \mathrm{min}$ through a reverse-phase $\mathrm{C}_{18}$ analytical column (Spheri-5, OD-MP, $10 \mathrm{~cm}$, Brownlee Lab., Santa Clara, CA) fitted with a $2.5 \mathrm{~cm}$ guard column of the same material. This solvent was not recycled. Unless otherwise indicated these conditions were used throughout the present investigations. Injection volumes of $25 \mu \mathrm{l}$ were chromatographed every $5 \mathrm{~min}$. Chromatographic peaks were identified according to retention times of standards containing inosine, hypoxanthine, and adenosine. The identity of the peaks was verified by incubating samples of adenosine with adenosine deaminase (Type VII, Sigma) or inosine with purine nucleoside phosphorylase (Sigma). Standard concentrations of hypoxanthine, inosine, and adenosine were used to calibrate the integrator at the beginning of every set of assays. Calibration was rechecked midway through each assay and at the end. ADA activity was determined as nmol of product (inosine plus hypoxanthine) formed $/ \mathrm{mg}$ protein $/ 30 \mathrm{~min}$ rather than as adenosine utilized since product formation was found to be a more sensitive and reproducible measure of enzyme activity. Depending on the amount of tissue used, however, adenosine utilization was found to equal inosine plus hypoxanthine formation using the assay conditions routinely employed. Assay blanks were calculated from samples in which endogenous levels of adenosine, inosine, and hypoxanthine were measured by adding tissue homogenates to reaction vessels already containing 20\% TCA. For each brain region and peripheral tissue assayed, reaction blanks were subtracted from the levels of products formed after incubation with $500 \mu \mathrm{M}$ adenosine. Protein was measured according to the method of Lowry et al. (1951) using BSA as standard.

\section{Perfused versus nonperfused brain regions}

The contribution of ADA activity in red blood cells to that in brain tissue was determined by measuring the activity in 6 brain regions (hypothalamus, superior colliculus, cerebellum, cerebral cortex, striatum, and hippocampus) taken from 8 animals that were either perfused transcardially with physiological saline or decapitated without perfusion. All 16 animals were anesthetized with chloral hydrate and 8 were perfused with $50 \mathrm{ml} 0.9 \%$ saline at room temperature over a period of $2 \mathrm{~min}$.

\section{Optimization of $A D A$ assay}

The establishment of the HPLC assay and characterization of ADA in CNS tissue required determination of the following: (1) completeness of purine separation under optimal HPLC conditions; (2) linearity with which the HPLC procedure detected purines; (3) efficiency of purine recovery from tissue homogenates; (4) effect of the detergent Triton $X-100$ on extraction of ADA activity during the homngenization procedure; (5) optimal substrate (adenosine) concentration and $K_{\mathrm{m}}$ and $V_{\max }$ values; (6) linearity of enzyme activity with respect to protein concentration in homogenates; and (7) optimal pH of the enzyme.

Chromatography of hypoxanthine, inosine, and adenosine was examined over the concentration range of 0.1-16.6 nmol $(5.2-667 \mu \mathrm{M})$ The linearity of UV detection was determined by comparing the known concentrations chromatographed with the integrated areas under the identified peaks using least-squares regression analyses. The efficiency of purine extraction from assay examples was determined for wholebrain homogenates after inactivation of enzymatic activity with $20 \%$ TCA. Hypoxanthine, inosine, and adenosine at $500 \mu \mathrm{M}$ concentrations were added to these inactivated samples, which were then neutralized and chromatographed. The peak areas were compared with those of standards of the same concentration, and the extraction efficiency was incorporated into all subsequent calculations.

Homogenization of brain tissue in the presence, as compared with the absence, of Triton X-100 has been found to enhance the activity of ADA (Pull and Mcllwain, 1974). The effect of up to 2\% Triton X-100 on ADA activity was therefore tested using the present assay incubation and homogenization conditions. Whole brain-as well as cerebellum, hypothalamus, hippocampus, midbrain, and thalamus-was homogenized with and without Triton X-100 using a Polytron and processed as described above. The brain subregions were tested in order to assess whether the detergent treatment had differential effects on ADA activity in brain regions previously reported to contain ADA-immunostaining of primarily perikarya or in those densely innervated by ADA-immunoreactive fibers (Nagy et al., 1984a).

The optimal substrate concentration for ADA was determined in brain by incubating homogenates containing 15.6, 31.2, 62.5, 125.0, 


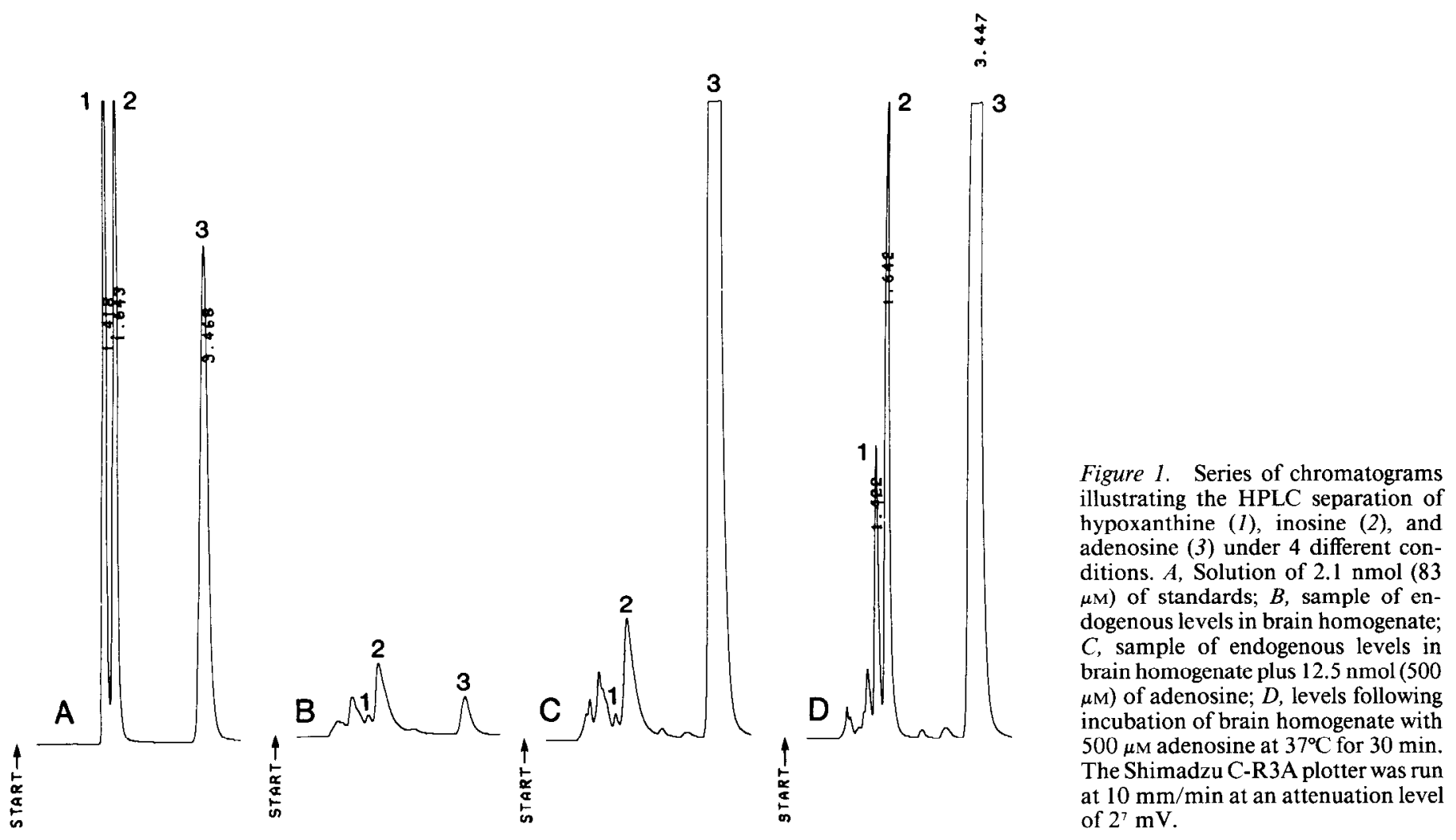

250.0 , or $500 \mu \mathrm{M}$ adenosine for $5,15,30$, and $60 \mathrm{~min}$. The initial velocities for these reactions were determined graphically, and these data were plotted as reciprocals of velocity (nmol product formed $/ \mathrm{mg}$ protein $/ 30 \mathrm{~min}$ ) versus substrate concentration $(\mu \mathrm{M})$. The $K_{\mathrm{m}}$ and $V_{\max }$ values were determined for whole brain, cerebellum, hippocampus, and anterior and posterior hypothalamus using a weighted least-squares analysis version of the Michaelis-Menten equation. The linearity of the assay with respect to enzyme concentration was examined by varying whole-brain homogenate protein content from 0.05 to $0.8 \mathrm{mg}$ in assays containing $500 \mu \mathrm{M}$ adenosine and adjusting incubation times so that not greater than $20 \%$ conversion of substrate occurred. The optimal $\mathrm{pH}$ for ADA activity in homogenates of whole brain was established using a "universal" buffer consisting of $20 \mathrm{~mm}$ each of sodium acetate, sodium phosphate, and Tris, the $\mathrm{pH}$ of which was adjusted to between 3.0 and 11.0 with phosphoric acid or $\mathrm{NaOH}$.

\section{Results}

Characterization of the $A D A$ assay

The HPLC separation of purines using the solvent system employed is shown in Figure 1. Adequate separation of endogenous (blank) and assay levels of hypoxanthine, inosine, and adenosine was obtained in homogenates. The retention times (min) were consistently 1.4 for hypoxanthine, 1.6 for inosine, and 3.5 for adenosine. The identity of the chromatographic peaks was confirmed by the metabolism of adenosine to inosine following incubation with purified ADA, and the metabolism of inosine to hypoxanthine by purine nucleoside phosphorylase. Purines were detectable at concentrations as low as $0.1 \mathrm{nmol}(5.2 \mu \mathrm{M})$ (Fig. 2) and their UV detection was linear to $16.6 \mathrm{nmol}(667$ $\mu \mathrm{M})$. The efficiency of adenosine, inosine, and hypoxanthine extraction from homogenates and HPLC measurement of the extract was found to be $91 \%$. The activity of ADA in brain homogenates was linear in the range of $0.05-0.8 \mathrm{mg}$ protein (Fig. 3) and optimal at pH 7.0 (Fig. 4) when incubations were for $30 \mathrm{~min}$ at $37^{\circ} \mathrm{C}$ using $500 \mu \mathrm{M}$ adenosine (Fig. 5). For every tissue, preliminary studies were conducted to verify that, at the protein concentration required for assay linearity (routinely less than $0.15 \mathrm{mg}$ ), a measurable amount of product was formed during the incubation period. All samples were measured in duplicate, and the variability between duplicates was typically

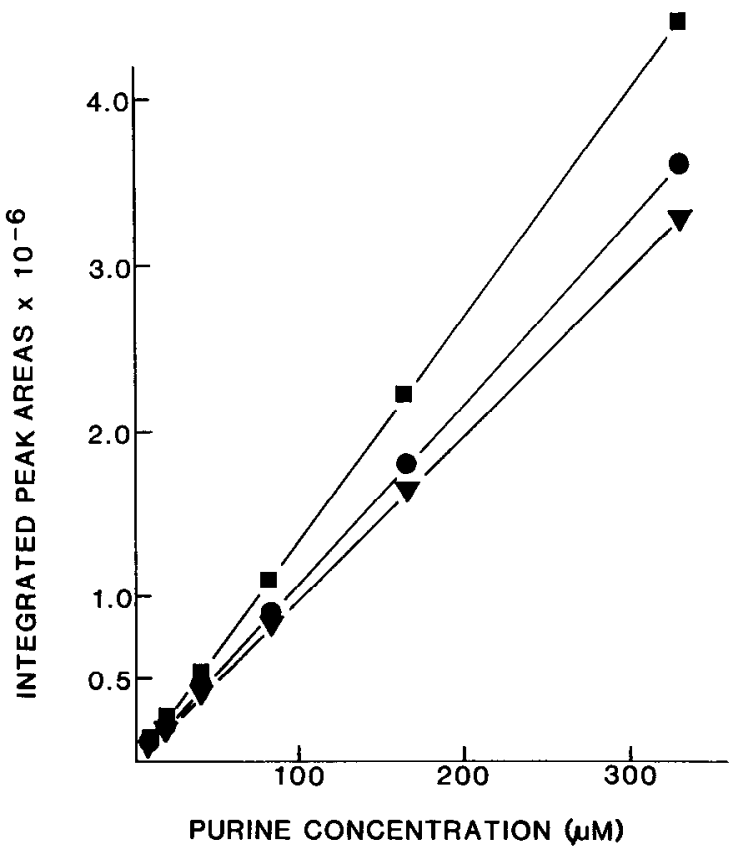

Figure 2. Linear relationship between the chromatography of different concentrations of adenosine $(\square)$, inosine $(\boldsymbol{\theta})$, and hypoxanthine $(\nabla)$ and their detection using the described HPLC technique. Illustrated points represent mean values from 3 determinations at each concentration. Variability among the triplicate samples was less than $1 \%$ for each purine. 


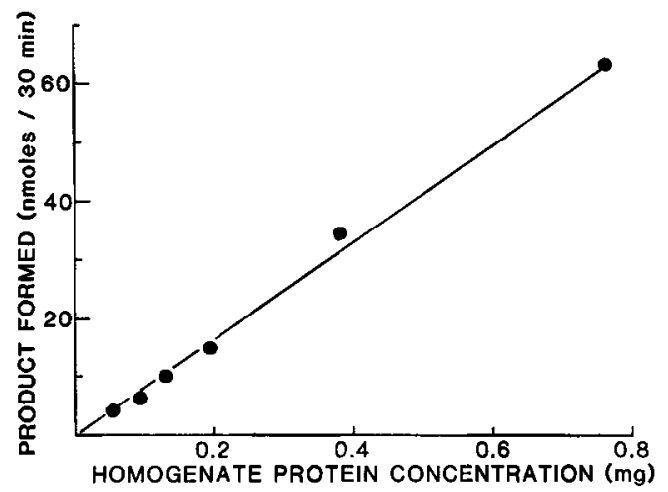

Figure 3. Linearity of ADA activity as a function of protein concentration in brain homogenates. Data points represent mean values of an assay performed in triplicate.

less than $10 \%$. Preliminary studies showed that freezing the tissue at $-80^{\circ} \mathrm{C}$ for up to 2 weeks had no effect on the levels of ADA activity as compared with those observed in freshly dissected tissue. On rare occasions it was necessary to store the final aqueous layer from the enzymatic assay. Purines in these samples were found to be stable during storage at $-20^{\circ} \mathrm{C}$ for $2-$ $3 \mathrm{~d}$, as indicated by calculations of enzymatic activity. The levels of ADA activity in homogenates of whole brain or of the 5 brain regions examined were not significantly different in the absence or presence of Triton X-100 at concentrations between 0.2 and $2 \%(\mathrm{vol} / \mathrm{vol})$ in the homogenization medium (data not shown).

The results of ADA activity measurements of 6 brain regions taken from normal or saline-perfused rats are shown in Table 1. Perfusion did not significantly change ADA activity in any arca other than cerebral cortex, where a small reduction of $14 \%$ was found. Therefore, this procedure was not employed in the subsequent regional analysis.

The derived $K_{\mathrm{m}}$ and $V_{\max }$ values taken from 3 independently conducted measures of ADA activity in whole brain, cerebellum, hippocampus, and anterior and posterior hypothalamus homogenates are shown in Table 2. Except for anterior hypothalamus, the $K_{\mathrm{m}}$ values for these tissues were not significantly different. Clearly, the posterior hypothalamus, as reflected by the $V_{\max }$ values, contains the highest ADA activity of the brain regions examined.

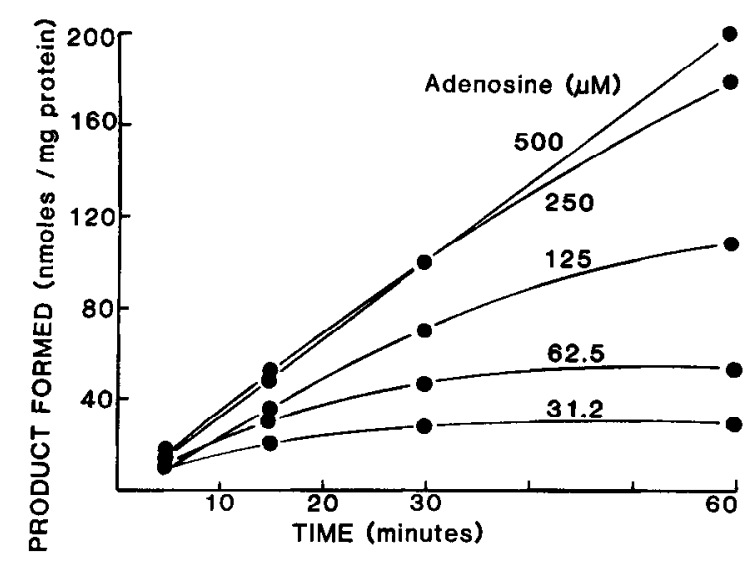

Figure 5. ADA activity in whole-brain homogenates incubated with adenosine concentrations of $31.2,62.5,125,250$, or $500 \mu \mathrm{M}$ for the time periods indicated. Each point is the mean of triplicate determinations, and the values are representative of 2 separate experiments.

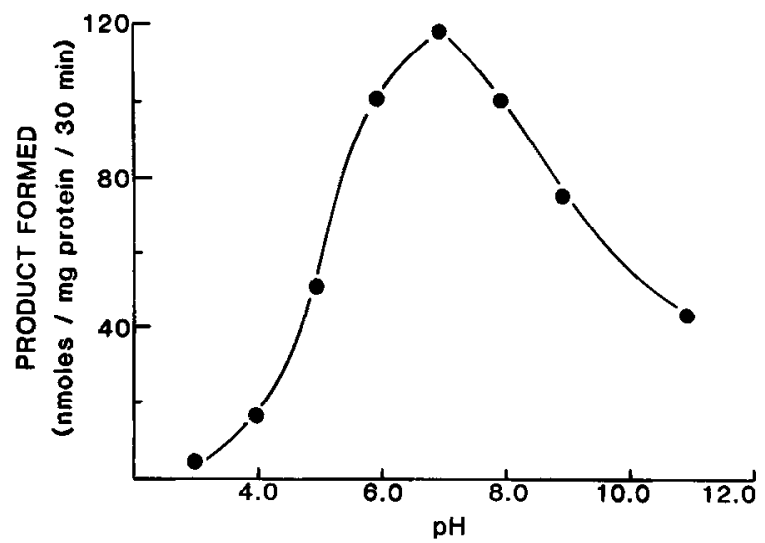

Figure 4. pH dependence of ADA activity in homogenates of whole brain. Values represent 2 separate experiments that yielded similar results.

\section{Regional distribution of ADA activity (Table 3)}

Within the forebrain about a 9-fold difference in ADA activity was found between the highest level of 279.2 in olfactory bulbs and the lowest activity of $31.6 \mathrm{nmol} / \mathrm{mg}$ protein $/ 30 \mathrm{~min}$ in whole hippocampus. Very little variation in ADA activity was noted among the $\mathrm{CA} 1, \mathrm{CA} 2, \mathrm{CA} 3$, and dentate gyrus subregions of the hippocampus. However, when dissected into segments along its septotemporal axis, ADA activity in the segment at the extreme temporal pole was nearly twice that observed in most of the other more dorsomedial hippocampal areas analyzed. Of the 7 cortical regions examined, the activities ranged from 84.0 in parietal cortex to $39.4 \mathrm{nmol} / \mathrm{mg}$ protein $/ 30 \mathrm{~min}$ in frontal cortex. The levels in olfactory and entorhinal areas were approximately equal to the level in parietal cortex. The enzymatic activity in the amygdala, septal nuclei, accumbens, and globus pallidus was roughly equal to $60 \mathrm{nmol} / \mathrm{mg}$ protein $/ 30 \mathrm{~min}$. Slightly lower activity was found in whole striatum, irrespective of whether the hcad, tail, or whole region was taken for assay. Corpus callosum was among the CNS areas containing the lowest levels of ADA activity.

In the diencephalon, a high level of activity was observed in hypothalamus; the posterior aspects and the posterior magnocellular nuclei, in particular, containcd the highest ADA activity

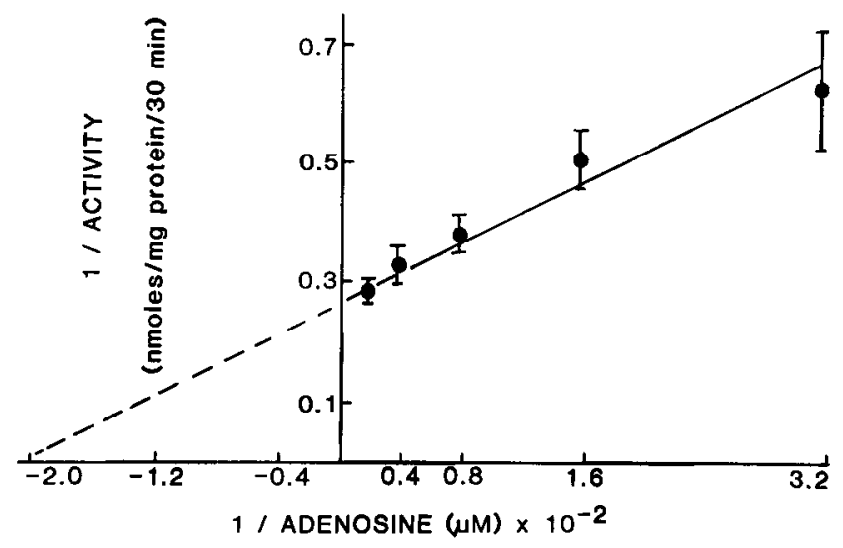

Figure 6. Double-reciprocal plot of ADA activity in whole-brain homogenates versus adenosine concentration. Incubations were for $30 \mathrm{~min}$ at $37^{\circ} \mathrm{C}$ using $0.3 \mathrm{mg}$ homogenate protein. Values represent means \pm SEM of 3 separate experiments. Regression line was drawn according to a weighted least-squares analysis. 
Table 1. Effect of animal perfusion on adenosine deaminase activity in discrete brain regions

Adenosine deaminase activity

(nmol product formed $/ \mathrm{mg}$ protein $/ 30 \mathrm{~min}$ )

\begin{tabular}{llll}
\cline { 2 - 3 } Brain region & \multicolumn{2}{l}{ Nonperfused } & \multicolumn{2}{l}{ Perfused } \\
\hline Hypothalamus & $277.6 \pm 14.0(6)$ & $290.2 \pm 8.0(6)$ \\
Superior colliculus & $142.0 \pm 9.4(6)$ & $151.6 \pm 22.0(6)$ \\
Cerebellum & $59.4 \pm 1.8(8)$ & $66.2 \pm 3.2(8)$ \\
Cortex & $56.0 \pm 2.4(6)$ & $48.4 \pm 2.2(6)^{a}$ \\
Striatum & $39.6 \pm 3.2(8)$ & $42.2 \pm 2.6(8)$ \\
Hippocampus & $39.2 \pm 2.8(8)$ & $39.6 \pm 2.4(8)$
\end{tabular}

Brains were obtained from rats anesthetized with chloral hydrate and sacrificed by decapitation prior to or following perfusion transcardially with $50 \mathrm{ml}$ of $0.9 \%$ $\mathrm{NaCl}\left(22^{\circ} \mathrm{C}\right)$. Values represent means $\pm \mathrm{SEM}$ of the number of animals indicated in parentheses. Statistical analyses were conducted using a 2-tailed Student's $t$ test. ${ }^{a} p<0.05$.

in brain, with the exception of choroid plexus. The heterogeneity of ADA activity in hypothalamus was further indicated by the 4-fold difference between levels in the lateral portion of the preoptic area and the posterior magnocellular nuclei. The level in habenula was about $50 \%$ higher than that in the thalamus, where activity ranged from 51.4 in the anterior lateral region to $86.8 \mathrm{nmol} / \mathrm{mg}$ protein $/ 30 \mathrm{~min}$ in the lateral geniculate nucleus.

In the mesencephalon and brain stem, the highest ADA activity $-147.2 \mathrm{nmol} / \mathrm{mg}$ protein $/ 30 \mathrm{~min}$ - was found in superior colliculus, within which the superficial layers had nearly twice the activity of deeper collicular layers. The lowest activity in the mesencephalon, nearly 4 times lower than superficial layers of superior colliculus, was observed in the inferior colliculus. The rest of the tissues examined in the mesencephalon and brain stem had ADA levels ranging from 104.4 in the substantia nigra to $64.0 \mathrm{nmol} / \mathrm{mg}$ protein $/ 30 \mathrm{~min}$ in cerebellum.

In spinal cord, the ADA levels in dorsal halves were consistently about $40 \%$ higher than levels in ventral halves at all rostrocaudal regions examined, including cervical, thoracic, and lumbar segments. The activity in lumbar white matter, 34.6 $\mathrm{nmol} / \mathrm{mg}$ protein $/ 30 \mathrm{~min}$, was substantially less than either lumbar dorsal or ventral gray matter. The activity in dorsal and ventral roots was about equal at 133.8 and $116.0 \mathrm{nmol} / \mathrm{mg}$ protein/30 min, respectively. The parasympathetic sphenopalatine ganglia demonstrated an activity of $834 \mathrm{nmol} / \mathrm{mg}$ protein/ $30 \mathrm{~min}$, which was twice that of the sympathetic superior cervical ganglia, $40 \%$ higher than pelvic ganglia, and 2-4 times higher than sensory ganglia. The ADA activity in optic, sciatic, saphenous, and vagus nerves was fairly uniform, ranging from 255.8 to $276.0 \mathrm{nmol} / \mathrm{mg}$ protein $/ 30 \mathrm{~min}$. Except for the very high activity in thymus $(4200 \mathrm{nmol} / \mathrm{mg}$ protein $/ 30 \mathrm{~min})$, the other peripheral tissues examined contained ADA activity ranging from 211.4 for anterior pituitary to $1450 \mathrm{nmol} / \mathrm{mg}$ protein/ 30 min for tongue epithelium.

\section{Discussion}

ADA activity in brain homogenates was maximum at $\mathrm{pH} 7.0$, a result similar to that previously reported (Arch and Newsholme, 1978; Mustafa and Tewari, 1970; Van der Weyden and Kelley, 1976). In the present study, treatment with $0.2-2.0 \%$ Triton X-100 did not affect levels of ADA activity. This finding is in agreement with reports by Arch and Newsholme (1978) and Van der Weyden and Kelley (1976), but not with the findings that homogenization of CNS tissue with $2 \%$ Triton X-100 augmented ADA activity by $48 \%$ (Mustafa, 1972; Pull and McIlwain, 1974). Therefore, it appears that the more vigorous homogenization using a Polytron as performed here obviates the
Table 2. Kinetic parameters of ADA activity in rat brain

\begin{tabular}{llc} 
& \multicolumn{2}{c}{ Adenosine deaminase activity } \\
\cline { 2 - 3 } Region & $K_{\mathrm{m}}(\mu \mathrm{M})$ & $\begin{array}{c}V_{\max }(\mathrm{nmol} / \mathrm{mg} \\
\text { protein/30 min })\end{array}$ \\
\hline Whole brain & $46.9 \pm 8.1$ & $106.8 \pm 6.2$ \\
Cerebellum & $32.6 \pm 8.1$ & $66.6 \pm 6.0$ \\
Hippocampus & $39.1 \pm 2.4$ & $35.8 \pm 8.0$ \\
Anterior hypothalamus & $24.4 \pm 4.9$ & $180.4 \pm 12.0$ \\
Posterior hypothalamus & $37.6 \pm 4.5$ & $477.8 \pm 27.6$ \\
\hline
\end{tabular}

Values represent means \pm SEM of 3 determinations.

need for treatment with this detergent. The $K_{\mathrm{m}}$ and $V_{\max }$ values for ADA activity in homogenates of whole brain were $47 \mu \mathrm{M}$ and $107 \mathrm{nmol} / \mathrm{mg}$ protein $/ 30 \mathrm{~min}$, respectively. Previously reported $K_{\mathrm{m}}$ values for CNS tissue included 17,34, and $100 \mu \mathrm{M}$ for whole brain and 54-57 $\mu \mathrm{M}$ for cerebral cortex (Arch and Newsholme, 1978; Phillips and Newsholme, 1979; Pull and Mcllwain, 1974; Skolnick et al., 1978). These same authors reported $V_{\max }$ values of $174,54,115$, and $105 \mathrm{nmol} / \mathrm{min} / \mathrm{g}$ wet weight tissue, respectively. Our calculated $V_{\max }$ value for whole brain was $308.2 \mathrm{nmol} / \mathrm{mg}$ tissue $/ \mathrm{min}$. Thus, the $K_{\mathrm{m}}$ and $V_{\max }$ values obtained here are similar to those previously reported for brain and agree well with the $K_{\mathrm{m}}$ values reported for periphcral tissucs, which ranged from 24 to $65 \mu \mathrm{M}$ in rat liver, heart, and gastrocnemius muscle (Arch and Newsholme, 1978); human mononuclear white blood cells (Morisaki et al., 1985); and bovine skeletal muscle (Martinez et al., 1984). In the present study, the $K_{\mathrm{m}}$ value for whole brain was not significantly different from that of the individual brain regions examined except for anterior hypothalamus, where it was found to be lower. Although repeatable, the reason for this difference is presently unclear, but it may be related to the very high density of axons as compared with cell bodies immunoreactive for ADA in the anterior hypothalamus; the kinetic characteristics of $\Lambda \mathrm{DA}$ may be dependent on its cellular localization. In this context, it should be noted that $V_{\max }$ values, where determined, were very similar to the levels of ADA activity measured using a single concentration $(500 \mu \mathrm{M})$ of adenosine.

The present results concerning the distribution of ADA activity in the rat CNS are in general agreement with the results of Phillips and Newsholme (1979), who examined this enzyme in 9 regions of human brain and found that hypothalamus contained nearly an order of magnitude greater activity than hindbrain, which contained the lowest activity. These results, however, are in marked contrast to the regional activities reported by several others (Davies and Taylor, 1979; Norstrand et al., 1984; Sun et al., 1976; Van der Weyden and Kelley, 1976). Sun et al. (1976) and Davies and Taylor (1979) examined brain regions in the rat and found ADA activity in the hypothalamus to be about 2 times higher than in striatum or neocortex. Van der Weyden and Kelley (1976) reported 3 times higher activity in human cerebrum than in cerebellum or spinal cord. Norstrand et al. (1984) found that white matter in frontal, orbital, and temporal cortical regions in human brain contained the highest ADA activity, with a 9-fold difference noted between these areas and spinal cord, the area with the lowest activity. They also reported relatively high levels of activity in the hippocampus compared with somewhat lower levels in the hypothalamus. These disparate findings may be due to species variations in ADA activity or differences in dissection procedures or assay methodologies. For example, Norstrand et al. (1984) employed a $1200 \times g$ supernatant as the source of ADA from human brain tissue, calculated activities on the basis of wet weight tissue, and measured ADA activity indirectly by quantitation of ammonia formation. 

Table 3. Distribution of adenosine deaminase activity in rat brain
and spinal cord

Adenosine deaminase activity $(\mathrm{nmol} / \mathrm{mg}$

Area protein $/ 30 \mathrm{~min})$

Telencephalon

Olfactory bulb

Olfactory cortex

Entorhinal cortex

Frontal cortex

Cingulate cortex

Temporal cortex

Striate cortex

Parietal cortex (sensory, motor)

Amygdala

Septal nuclei

Hippocampus (whole)

$\mathrm{CA} 1$
$\mathrm{CA} 2$
$\mathrm{CA} 3$

Dentate gyrus

Septal pole

Segment 1

Segment 2

Segment 3

Segment 4

Segment 5

Temporal pole, segment 6

Accumbens

Striatum (whole)

Head of striatum

Tail of striatum

Globus pallidus

Bed nucleus of stria terminalis

Corpus callosum

Diencephalon

Thalamus (whole)

Anterior medial

Anterior lateral

Posterior medial

Posterior lateral

Lateral geniculate nucleus

Medial geniculate nucleus

Hypothalamus (whole)

Anterior half

Posterior half

Preoptic area, medial

Preoptic area, lateral

Anterior hypothalamic area, medial

Anterior hypothalmic area, lateral

Posterior magnocellular nuclei

Habenula

$279.2 \pm 13.6$

$77.8 \pm 4.0$

$80.8 \pm 16.8$ (4)

$39.4 \pm 4.8$

$67.0 \pm 4.0$

$56.6 \pm 7.6 \quad$ (4)

$58.8 \pm 6.8$

$84.0 \pm 11.0$ (4)

$61.4 \pm 6.6 \quad$ (6)

$72.2 \pm 3.4$

$31.6 \pm 1.6 \quad(6)$

$40.4 \pm 4.8$

$33.6 \pm 2.8$

$35.2 \pm 3.0$

$31.8 \pm 2.0$

$44.2 \pm 3.0$

$34.0 \pm 1.0 \quad$ (5)

$35.6 \pm 1.6 \quad$ (5)

$34.4+1.0$ (5)

$39.6 \pm 1.8$

$63.2 \pm 2.8$

$60.2 \pm 3.0 \quad$ (6)

$37.2 \pm 2.0 \quad(10)$

$40.2 \pm 2.0$

$48.2 \pm 2.4$

$60.6 \pm 4.4 \quad$ (5)

$83.2 \pm 2.6 \quad$ (5)

$38.8 \pm 2.4$

$61.4 \pm 3.4$

$74.6 \pm 5.6$

$51.4 \pm 2.8$

$80.4 \pm 2.6$

$66.6 \pm 1.6$

$86.8 \pm 3.8$

$85.0 \pm 5.6$

$207.8 \pm 11.4$ (11)

$168.0 \pm 12.6$ (5)

$390.6 \pm 9.6 \quad(5)$

$138.2 \pm 5.6 \quad(5)$

$98.0 \pm 6.6$

$134.6 \pm 7.8 \quad$ (4)

$125.0 \pm 13.2$ (4)

$420.4 \pm 52.0$ (4)

$122.0 \pm 6.8$

$70.2 \pm 3.6 \quad(5)$

$147.2 \pm 7.4$

$181.0 \pm 13.6(6)$

$106.4 \pm 6.4 \quad(6)$

$52.8 \pm 3.2$

$92.0 \pm 4.6$

Midbrain (whole)

Superior colliculus (whole)

Superficial layers

Deep layers
Table 3. Continued

Area

Adenosine deaminase activity $(\mathrm{nmol} / \mathrm{mg}$ protein $/ 30 \mathrm{~min}$ )

Substantia nigra

$104.4 \pm 4.0$

Reticular formation

$82.4 \pm 7.8$

Brain stem

Pons

Medulla

$71.2 \pm 6.6 \quad(8)$

$94.8 \pm 7.2 \quad(8)$

Cerebellum

Choroid plexus

$64.0 \pm 3.2$

$466.2 \pm 10.0$

Spinal cord

Spinal cord (whole)

$42.0 \pm 2.8$

Cervical

Dorsal

Ventral

Thoracic

Dorsal

Ventral

Lumbar

Dorsal

Ventral

Dorsal gray

Ventral gray

White matter

Dorsal roots

Ventral roots

$83.2 \pm 2.8 \quad$ (6)

$58.8 \pm 4.2 \quad$ (6)

$96.6 \pm 9.0 \quad(6)$

$62.8 \pm 8.6$

$103.2 \pm 7.8 \quad(6)$

$73.8 \pm 5.6$

$103.6 \pm 7.2$

$72.2 \pm 6.2$

$34.6 \pm 2.6 \quad$ (5)

$133.8 \pm 24.0$ (6)

$116.0 \pm 11.4$ (5)

Ganglia

Sensory

Trigeminal

$218.8 \pm 18.2$ (6)

Lumbar

Parasympathetic

Sphenopalatine

Pelvic

Sympathetic

Superior cervical

$394.6 \pm 24.0$

$834.0 \pm 112.0(7)$

$600.0 \pm 38.0$

$407.6 \perp 21.8 \quad(5)$

Nerves

Optic

Sciatic

Saphenous

Vagus

$255.8 \pm 28.4$ (5)

$276.0 \pm 34.6 \quad(6)$

$250.8 \pm 40.6$ (5)

$450.8 \pm 40.6 \quad(5)$

Peripheral tissues

Retina

Anterior pituitary

$80.6 \pm 3.6 \quad(8)$

$211.4 \pm 10.8$ (10)

$302.8 \pm 18.2 \quad(5)$

$350.4 \pm 23.0$

$460.4 \pm 21.2$

$492.2 \pm 14.8$ (8)

$337.0 \pm 22.0$

$1450.0 \pm 79.0 \quad(6)$

$4200.0 \pm 268.0(7)$

Pineal gland

Adrenal gland

Lung

Liver

Epithelium (tongue)

Thymus

Values represent means \pm SEM of the number of determinations indicated in parentheses.

Interpretation of the possible functional significance of the markedly heterogeneous distribution of ADA activity within the CNS and among peripheral tissues requires consideration of the role of ADA in the intracellular metabolism of adenosine. 
Additionally, it necessitates comparison of the present results with previous reports on the immunohistochemical localization of ADA in the CNS and the distribution of ${ }^{3} \mathrm{H}-\mathrm{NBI}$ binding to putative nucleoside transport sites in brain.

Observations that high concentrations of adenosine are cytotoxic indicate the requirement to maintain subtoxic levels of this nucleoside (Fox and Kelley, 1978). Intracellularly, adenosine can be incorporated into $S$-adenosylhomocysteine via the enzyme $S$-adenosylhomocysteine hydrolase (AH), phosphorylated by adenosine kinase (AK) to $5^{\prime}$-AMP, or deaminated by ADA. Although AK has a higher affinity than ADA for adenosine, under basal conditions the enzyme appears to be close to saturation (Arch and Newsholme, 1978). Also, the formation of $S$-adenosylhomocysteine has been shown to be only a minor product in brain slices even after they are exposed to relatively high concentrations of adenosine (Reddington and Pusch, 1983). Therefore, ADA may play a greater role than AK or $\mathrm{AH}$ in regulating adenosine concentrations under conditions where adenosine levels are markedly increased. This notion is supported by reports showing that seizure activity in animals or exposure of CNS tissues to depolarization or hypoxic conditions causes marked increases in inosine and hypoxanthine levels with little change in $5^{\prime}$-AMP levels (Daval and Barberis, 1981; Lewin and Bleck, 1981, 1983).

In the present study, a heterogeneous distribution of ADA activity was found within the CNS and among peripheral tissues examined, and particularly high activities were observed in discrete and diverse regions of the brain. For CNS tissues, the highest levels were found in the choroid plexus, posterior hypothalamic magnocellular nuclei, olfactory bulbs, and superficial layers of superior colliculus. The lowest levels were in subregions of the hippocampus and the corpus callosum. In spinal cord, the activity was relatively low, with that in dorsal regions significantly greater than in ventral regions. In contrast, the activity in ganglia, nerves, and other tissues was higher than that observed in CNS tissues, with thymus clearly containing the highest ADA activity of any tissue examined. This latter finding is in concert with previous reports (Chechik et al., 1983). Additionally, the ADA levels reported in rat liver and lung were similar to those previously reported for human tissue (Van der Weyden and Kelley, 1976). Consistent with studies on the immunohistochemical localization of ADA in rat CNS (Nagy and Daddona, 1985; Nagy et al., 1984, 1985), the regions that con tain ADA-immunoreactive perikarya or fibers also contain the highest activity of ADA. This is especially true for the posterior basal region of the hypothalamus, where immunoreactive cell bodies are found in the tuberal, caudal, and postmammillary caudal magnocellular nuclei, and in the anterior hypothalamus, where ADA-immunostaining of fibers is particularly dense in medial areas. The relatively higher activities in superficial layers of the superior colliculus, habenula, olfactory bulbs, and dorsal as compared with ventral spinal cord, is also consistent with observations of intense ADA immunostaining of fibers and/or cell bodies in these areas. The greater ADA activity in the temporal compared with the septal pole of the hippocampus coincides with findings that ADA-immunostained fibers are more abundant in the former than the latter region (W.S. Staines and J. I. Nagy, unpublished observations). Due to limitations imposed by dissection techniques, however, high ADA activity in very small nuclei that contain ADA-immunoreactive elements is not reflected in the present measurements of $\mathrm{ADA}$; in some instances, the samples taken for assay contained a disproportionately greater amount of tissue that lacks or exhibits sparse ADA-immunostaining relative to a constituent subregion within which intense immunoreactivity is observed. It is likely, for example, that the medial habenula, which displays very dense ADA immunostaining of what we suspect to be axons and terminals, contains much greater ADA activity than indicated by the present measurements of whole habenula since ADA-immunoreactive elements in the relatively larger lateral subnucleus are scarce. Similarly, because of its dispersed anatomical configuration (Senba et al., 1985b), it was difficult to dissect posterior hypothalamic magnocellular nuclei from surrounding tissue. The ADA activity in the ADA-immunopositive cell groups comprising this nucleus may be substantially higher than presently reported.

The diverse physiological actions of adenosine are believed to be mediated extracellularly through its receptors. Access of extracellular adenosine to ADA, which appears to be primarily a cytoplasmic enzyme, is contrulled mainly by the nucleoside transport system and, to a limited extent, by passive diffusion through membranes (Plagemann and Wohlhueter, 1980; Wu and Phillis, 1984). The nucleoside transport system is potently inhibited by NBI in peripheral tissues, and recently ${ }^{3} \mathrm{H}-\mathrm{NBI}$ binding sites have been demonstrated in CNS tissues (Geiger, 1986; Geiger et al., 1985; Hammond and Clanachan, 1984; Marangos et al., 1982). In a previous report, we found a close correspondence between brain areas containing structures immunoreactive for ADA and those containing high levels of ${ }^{3} \mathrm{H}$ NBI binding sites as demonstrated by autoradiographic and membrane binding methods (Geiger and Nagy, 1984; Nagy et al., 1985). Here, we found a significant correlation of $r=0.830$ between levels of ADA activity and ${ }^{3} \mathrm{H}-\mathrm{NBI}$ binding sites when comparisons involved discrete brain regions richly endowed with fibers immunoreactive for ADA. However, a correlation coefficient of $r=0.239$ was obtained if comparisons included brain regions, such as whole thalamus or midbrain, that are more heterogeneous with respect to their subnuclei organization. In the thalamus, for example, the extreme medial nuclei contain grcater quantities of $\mathrm{ADA}$-immunoreactive fibers, $\Lambda \mathrm{D} \Lambda$ activity, and ${ }^{3} \mathrm{H}-\mathrm{NBI}$ binding sites compared with the bulk of the lateral areas. Thus, although there is strong circumstantial evidence pointing to a biochemical and anatomical relationship between $\mathrm{ADA}$ and ${ }^{3} \mathrm{H}-\mathrm{NBI}$ binding sites in the rat $\mathrm{CNS}$, more direct methods and a finer level of analysis are now required to establish the exact nature of this relationship.

\section{References}

Agarwal, R. P., S. M. Sagar, and R. E. Parks, Jr. (1975) Adenosine deaminase from human erythrocytes. Purification and effects of adenosine analogs. Biochem. Pharmacol. 24: 693-701.

Akasu, T., P. Shinnick-Gallagher, and J. P. Gallagher (1984) Adenosine mediates a slow hypcrpolarizing synaptic potential in autonomic neurons. Nature 311: 62-64.

Andy, R. J., and R. Kornfeld (1982) The adenosine deaminase binding protein of human skin fibroblasts is located on the cell surface. J. Biol. Chem. 257: 7922-7928.

Arch, J. R. S., and E. A. Newsholme (1978) Activities and some properties of $5^{\prime}$-nucleotidase, adenosine kinase and adenosine deaminase in tissues from vertebrates and invertebrates in relation to the control of the concentration and the physiological role of adenosine. Biochem. J. 174: 965-977.

Chechik, B. E., R. Baumal, and S. Sengupta (1983) Localization and identity of adenosine deaminase-positive cells in tissues of the young rat and calf. Histochem. J. 15: 373-387.

Daddona, P. E., B. S. Mitchell, H. J. Meuwissen, B. L. Davidson, J. M Wilson, and C. A. Koller (1983) Adenosine deaminase deficiency with normal immune function. An acidic enzyme mutation. J. Clin. Invest. 72: 483-492.

Daval, J. L., and C. Barberis (1981) Release of radiolabelled adenosine derivatives from superfused synaptosome beds. Evidence for the output of adenosine. Biochem. Pharmacol. 30: 2559-2567.

Davies, L. P., and K. M. Taylor (1979) Rat brain guanine deaminase; correlation with regional levels of cyclic GMP phosphodiesterase. J. Neurochem. 33: 951-952.

Fox, I. H., and W. N. Kelley (1978) The role of adenosine and 2'deoxyadenosine in mammalian cells. Annu. Rev. Biochem. 45: 655686.

Geiger, J. D. (1986) Localization of $\left[{ }^{3} \mathrm{H}\right]$ cyclohexyladenosine and 
$\left[{ }^{3} \mathrm{H}\right]$ nitrobenzylthioinosine binding sites in rat striatum and superior colliculus. Brain Res. 363: 404-408.

Geiger, J. D., and J. I. Nagy (1984) Heterogeneous distribution of adenosine transport sites labelled by $\left[{ }^{3} \mathrm{H}\right]$ nitrobenzylthioinosine in rat brain: An autoradiographic and membrane binding study. Brain Res. Bull. 13: 657-666.

Geiger, J. D., and J. I. Nagy (1985) Localization of $\left[{ }^{3} \mathrm{H}\right] \mathrm{ni}-$ trobenzylthioinosine binding sites in rat spinal cord and primary afferent neurons. Brain Res. 347: 321-327.

Geiger, J. D., F. S. LaBella, and J. I. Nagy (1985) Characterization of nitrobenzylthioinosine binding to nucleoside transport sites selective for adenosine in rat brain. J. Neurosci. S: 735-740.

Giblett, E. R., J. E. Anderson, F. Cohen, B. Pollara, and H. J. Meuwissen (1972) Adenosine deaminase deficiency in two patients with severely impaired cellular immunity. Lancet 2: 1067-1069.

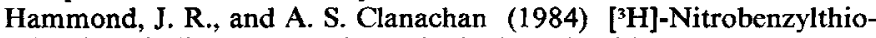
inosine binding to the guinea pig CNS nucleoside transport system: A pharmacological characterization. J. Neurochem. 43: 1582-1592.

Hartwick, R., A. Jeffries, A. Krstullovic, and P. R. Brown (1978) An optimized assay for adenosine deaminase using reverse phase high pressure liquid chromatography. J. Chromatogr. Sci. 16: 427-435.

Konig, J. F. R., and R. A. Klippel (1963) The Rat Brain: A Stereotaxic Atlas of the Forebrain and Lower Parts of the Brain Stem, Williams \& Wilkins, Baltimore, MD.

Lewin, E., and V. Bleck (1981) Electroshock seizures in mice: Effect on brain adenosine and its metabolites. Epilepsia 22: 577-581.

Lewin, E., and V. Bleck (1983) Pentylenetetrazol seizures in mice: Effect on brain inosine and hypoxanthine. Neuropharmacology 22 : 665-668.

Lowry, O. H., N. J. Rosebrough, A. L. Farr, and R. J. Randall (1951) Protein measurements with the folin phenol reagent. J. Biol. Chem. 193: 265-275.

Major, P. P., R. P. Agarwal, and D. W. Kufe (1981) Clinical pharmacology of deoxycoformycin. Blood 58: 91-96.

Marangos, P. J., J. Patel, R. Clark-Rosenberg, and A. M. Martino (1982) $\left[{ }^{3} \mathrm{H}\right]$ Nitrobenzylthioinosine binding as a probe for the study of adenosine uptake sites in brain. J. Neurochem. 39: 184-191.

Martinez, C., J. M. Fumalacarrequi, V. Diez, and J. Burgos (1984) Bovine skeletal muscle adenosine deaminase. Purification and some properties. Int. J. Biochem. 16: 1279-1282.

Morisaki, T., H. Fujci, and S. Miwa (1985) Adenosine deaminase (ADA) in leukemia: Clinical value of plasma ADA activity and characterization of leukemic cell ADA. Am. J. Hematol. 19: 37-45.

Mustafa, S. J. (1972) Latent adcnosinc dcaminase activity in rat brain. Pathol. Microbiol. 38: 388-390.

Mustafa, S. J., and C. P. Tewari (1970) Latent adenosine deaminase in mouse brain. II. Purification and properties of mitochondrial and supernatant adenosine deaminase. Biochim. Biophys. Acta 220:326337.

Nagy, J. I., and P. E. Daddona (1985) Anatomical and cytochemical relationships of adenosine deaminase-containing primary afferent neurons in the rat. Neuroscience 15: 799-813.

Nagy, J. I., L. A. LaBella, M. Buss, and P. E. Daddona (1984a) Immunohistochemistry of adenosine deaminase: Implications for adenosine neurotransmission. Science 224: 166-168.

Nagy, J. I., L. A. LaBella, and P. E. Daddona (1984b) Purinergic mechanisms in antidromic vasodilation and neurogenic inflamation. In Antidromic Vasodilation and Neurogenic Inflammation, J. A. Chahl, J. Szolesanyi, and F. Lembeck, eds., pp. 193-206, Hungarian Akademia, Kaido, Hungary.
Nagy, J. I., J. D. Geiger, and P. E. Daddona (1985) Adenosine uptake sites in rat brain: Identification using ${ }^{3}$ II-nitrobenzylthioinosine and colocalization with adenosine deaminase. Neurosci. Lett. 55:47-53.

Norstrand, I. F., V. C. Siverls, and R. M. Libbin (1984) Regional distribution of adenosine deaminase in the human neuraxis. Enzyme $32: 20-25$.

Paxinos, G., and C. Watson (1982) The Rat Brain in Stereotaxic Coordinates, Academic, New York.

Phillips, E., and E. A. Newsholme (1979) Maximum activities, properties and distribution of 5 -nucleotidase, adenosine kinase and adenosine deaminase in rat and human brain. J. Neurochem. 33: 553558.

Phillis, J. W., and P. H. Wu (1981) The role of adenosine and its nucleotides in central synaptic transmission. Prog. Neurobiol. 16: 187-239.

Phillis, J. W., J. P. Edstrom, G. K. Kostopoulos, and J. R. Kirkpatrick (1979) Effects of adenosine and adenine nucleotides on synaptic transmission in the cerebral cortex. Can. J. Physiol. Pharmacol. 57: $1289-1312$.

Phillis, J. W., G. Preston, and R. E. DeLong (1984) Effects of anoxia on cerebral blood flow in the rat brain: Evidence for a role of adenosine in autoregulation. J. Cerebr. Blood Flow Metab. 4: 586-592.

Phillis, J. W., R. E. DeLong, and J. K. Towner (1985) Adenosine deaminase inhibitors enhance cerebral anoxic hyperemia in the rat. J. Cerebr. Blood Flow Metab. 5: 295-299.

Plagemann, P. G. W, and R. M. Wohlhueter (1980) Permeation of nucleosides, nucleic acid bases and nucleosides, nucleic acid bases, and nucleotides in animal cells. Curr. Top. Membr. Transp. 13:225330.

Pull, I., and H. Mcllwain (1974) Rat cerebral cortex adenosine deaminase activity and its subcellular distribution. Biochem. J. 144: $37-41$.

Radulovacki, M., R. M. Virus, M. Djuricic-Nedelson, and R. D. Green (1983) Hypnotic effects of deoxycoformycin in rats. Brain Res. 271: 392-395.

Reddington, M., and R. Pusch (1983) Adenosine metabolism in a rat hippocampal slice preparation: Incorporation into S-adenosylhomocysteine. J. Neurochem. 40: 285-290.

Senba, E., P. E. Daddona, T. Watanabe, J. Y. Wu, and J. I. Nagy (1985a) Coexistence of adenosine deaminase, histidine decarboxylase and glutamate decarboxylase in hypothalamic neurons of the rat. J. Neurosci. 5: 3393-3402.

Senba, E., P. E. Daddona, and J. I. Nagy (1985b) Immunohistochemical demonstration of adenosine deaminasc in preganglionic parasympathetic neurons in the rat. Soc. Neurosci. Abstr. 11 (Pt. 2): 1027.

Skolnick, P., Y. Nimitkitpaisan, L. Stalvey, and J. W. Daly (1978) Inhibition of brain adenosine deaminase by 2 -deoxycoformycin and erythro-9-(2-hydroxy-3-nonyl) adenine. J. Neurochem. 30: 1579-1582.

Stone, T. W. (1981) Physiological roles for adenosine and adenosine 5 '-triphosphate in the nervous system. Neuroscience 6: 523-555.

Sun, M.-C., H. Mcllwain, and I. Pull (1976) The metabolism of adenine derivatives in different parts of the brain of the rat, and their release from hypothalamic preparations on excitation. J. Neurobiol. 7: $109-122$.

Van der Weyden, M. B., and W. N. Kelley (1976) Human adenosine deaminase. Distribution and properties. J. Biol. Chem. 251: 54485456.

Wu, P. H., and J. W. Phillis (1984) Uptake by central nervous tissue as a mechanism for the regulation of extracellular adenosine concentrations. Neurochem. Int. 6: 613-632. 